\title{
Development of polyvinyl acetate thin films by electrospinning for sensor applications
}

\author{
Amith Veerabhadraiah ${ }^{1}$ - Sridhar Ramakrishna ${ }^{1}$ - Gangadhar Angadi ${ }^{1}$. \\ Mamtha Venkatram ${ }^{1}$ - Vishnumurthy Kanivebagilu Ananthapadmanabha ${ }^{2}$. \\ Narasimha Murthy Hebbale NarayanaRao ${ }^{1} \cdot$ Krishna Munishamaiah $^{1}$
}

Received: 4 May 2017/ Accepted: 11 July 2017 / Published online: 22 July 2017

(c) The Author(s) 2017. This article is an open access publication

\begin{abstract}
Electrospinning is an effective process for synthesis of polymer fibers with diameters ranging between nanometers and micrometers by employing electrostatic force developed due to application of high voltage. The present work aims to develop an electrospinning system and optimize the process parameters for synthesis of Polyvinyl Acetate thin films used for gas and humidity sensors. Taguchi's Design of Experiment was adopted considering three main factors at three different levels for optimization of process parameters. The factors considered were flow rate $(0.5,0.6$ and $0.7 \mathrm{ml} / \mathrm{h})$, voltage $(18,19$ and $20 \mathrm{kV}$ ) and spinneret to collector distance $(8,9,10 \mathrm{~cm})$ with fiber diameter as the response factor. The main effect plots and interaction plots of the parameters were studied to determine the most influencing parameter. Flow rate was the most significant factor followed by spinneret to collector distance. Least fiber diameter of $24.83 \mathrm{~nm}$ was observed at $19 \mathrm{kV}, 0.5 \mathrm{ml} / \mathrm{h}$ flow rate and $8 \mathrm{~cm}$ spinneret to collector distance. SEM images revealed uniform fiber diameter at lower flow rate while bead formation increased monotonically with rise in flow rate.
\end{abstract}

Keywords Electrospinning - Polyvinylacetate · Thin films $\cdot$ Design of experiment $\cdot$ SEM

Amith Veerabhadraiah amith.amith4@gmail.com

1 Department of Mechanical Engineering, R. V. College of Engineering, Bengaluru, Karnataka, India

2 Department of Chemistry, R. V. College of Engineering, Bengaluru, Karnataka, India

\section{Introduction}

Research on thin films is evolving at a rapid pace because of their wide applications in areas such as microelectronics, wear resistance coatings, optical coatings and biological implants. Increased sensitivity of thin films has led to interest in nanostructured materials such as nanofibers and nanowebs (Dinga et al. 2010). Researchers have found the importance of polymers for the development of chemical sensors, membrane separation, solid phase extraction and chromatography (Mirmohseni and Oladegaragoze 2003). Methods for the development of micro and nanofibers from thermoplastic polymers includes melt-blowing, gel spinning, drawing, template phase separation and spun-bound fibers which are dependent on mechanical forces for extruding polymers. Typical fiber diameter formed by these methods is in the order of $10-150 \mu \mathrm{m}$, which is inadequate for thin film applications. Electrospinning uses high voltage for the generation of polymer thin films with fiber diameter in the range 10-500 $\mathrm{nm}$ depending on the process parameters (Wang et al. 2012; Kiyak and Cakmak 2014). The simplicity of the technique along with cost effectiveness and higher rates of production makes the process more promising. Table 1 provides a comparison of different techniques used for polymer thin films and their average fiber diameter. The ability of polymers to undergo molecular interaction with many other species of research interest and thin film formation makes it widely used in sensor applications.

Fundamentally, an electrospinning system consists of a needle as anode, fiber collecting substrate as cathode, high voltage power supply between 5 and $30 \mathrm{kV}$ to influence the transfer of polymer jet onto the collector plate, an injection system to supply polymer at a constant flow rate in the orders of few micro to milliliters, and a suitable solvent to dissolve the polymer (Malshe et al. 2011). The operational parameters 
Table 1 Various techniques for the development of polymer fibers

\begin{tabular}{lll}
\hline Technique & Demerits & Average diameter \\
\hline Melt blowing & Produces discontinuous fibers and low strength & $10-500 \mu \mathrm{m}$ \\
Gel spinning & Non-repeatability & $10-200 \mu \mathrm{m}$ \\
Drawing & Limited to viscoelastic materials and results in a single fiber & $100 \mu \mathrm{m}$ \\
Template & Development of continuous fiber not possible & $100-200 \mu \mathrm{m}$ \\
Phase separation & Becomes porous and non-uniform & $300 \mu \mathrm{m}$ \\
Electrospinning & Beads are formed along with fibers & $10 \mathrm{~nm}$-hundreds of nm \\
\hline
\end{tabular}

are not only dependent on the material properties but also on the viscosity of the polymer solution. High voltage supply and flow rate are the most influencing parameters on the fiber diameter, whereas the concentration of polymer solution and distance between the spinneret and collector are the parameters that affect the morphology of nanofibers (Pankonian et al. 2011). Different polymeric systems have been investigated for the development of nanofibers using electrospinning technique and the parameters considered at the first level are solution viscosity, polymer concentration and molecular weight. Viscosity of the polymer solution mainly depends on the molecular weight of the polymer and its concentration in the solvent. High molecular weight polymer is preferable for the development of continuous fibers (Pise et al. 2013). Strong electrical repulsive force at the anode reduces the polymer Taylor cone to thin fiber; flow rate determines the fiber diameter and bead formation. Spinneret to collector distance with sufficient voltage gradient produces fibers with minimum beads.

However, the influence of electrospun variables and associated fibrous structures is still not well-understood to achieve bead-free nanofibers with good dimensional stability (Albetrana et al. 2015). Different thermoplastic polymers have been studied for optimization of electrospinning parameters. Researchers dissolved thermoplastic polymers in dimethyl formamide (DMF) to produce fibers by electrospinning technique. The authors emphasized the significance of electrospinning distance for generation and ease of fiber collection (Chaudhary and Ahuja 2014). In another approach, thermoplastic polymer solution was spun by varying input parameters such as concentration, voltage, flow rate, distance between collector and syringe tip. Taguchi's Design of Experiments ( $\mathrm{L}_{9}$ ) was used for optimization. Fiber diameter increased with concentration, decreased with increase in voltage resulting in fewer bead formations. In another investigation involving Design of Experiments, five factors at three levels with $\mathrm{L}_{18}$ orthogonal array was studied. The most significant factor was found to be polymer concentration followed by feed rate (Khanlou and Ang 2014). A strong electric field assisted electrospinning method is more efficient to steer fibers towards the collector plate. The bending instability of jet in electrospinning process is eliminated due to the focused electric field force (Cui et al. 2011). The collectability of fibers, fiber diameter, orientation and fiber porosity are strongly affected by the solution properties and processing parameters (Dinga et al. 2009; Teo et al. 2011).

Polyvinylacetate (PVAc) is a homopolymer synthesized from vinylacetate monomer via a free radical polymerization technique. PVAc a synthetic polymer that finds application for detection of gas, moisture and humidity. PVAc films are used for oral drug delivery products and also as emission sensors for vehicles (Park et al. 2008). Investigations of PVAc thin films and their nanocomposites prepared by electrospinning method and its effect on electric potentials and distance on the morphology and diameter of fibers are reported (Ghanbari et al. 2016). Nanofibers of polyvinylalcholo and polyvinylacetate composite in the ratio of 50:50 blend loaded with ciprofloxacin HCI (CipHCI) was prepared by electrospinning technique to develop biomedicated nanofiber electrospun mats for controlled drug release (Jannesari et al. 2011). The concentration of solution and applied voltage was decisive to regulate the diameter of PVAc nanofibers (Petrasa et al. 2011; Park et al. 2011; Nirmala et al. 2014).

Review of literature suggests, although investigations on development of thin films using electrospinning is reported, studies focusing on the design and development of electrospinning systems is very scarce. Hence, the present study focuses on development of a cost effective electrospinning system and optimization of process parameters for development of PVAc thin films dissolved in DMF. The resulting nanofibers were systematically characterized.

\section{Materials and experimental procedure}

\section{Materials}

Polyvinylacetate of molecular weight $M_{\mathrm{w}}=30,000 \mathrm{~g} / \mathrm{mol}$ supplied from Sigma Aldrich, Bangalore, India and dimethylformamide from M/s Vasu Scientifics, Bangalore, India was used. 


\section{Preparation of PVAc and DMF solution}

PVAc as polymer and DMF as solvent were used for solution preparation. PVAc to DMF in the ration $6 \mathrm{~g}: 30 \mathrm{~g}$ was used to obtain a viscous solution. The mixture of PVAc and DMF was stirred using double bead magnetic stirrer for $48 \mathrm{~h}$ to get homogenous solution ( $24 \mathrm{~h}$ clockwise and $24 \mathrm{~h}$ anticlockwise).

\section{Basic setup of electrospinning system}

The electrospinning apparatus comprised of an injection pump, high voltage power supply, fixture to support spinneret and collector plate. Spinneret was connected to the positive terminal of voltage supply, collector plate to negative terminal and grounded through a high gauge copper strip. Spinneret and collector plate was mounted on the fixture. Spinneret was connected to syringe containing polymer solution through a Teflon tube. Syringe was mounted on the injection system to pump the polymer solution at required flow rate.

\section{Design of fixture}

The fixture was designed to mount collector plate and spinneret as shown in Fig. 1a, b. The collector plate and spinneret are in perpendicular planes with respect to the fixture axis. Two holes were laser drilled in the fixture to connect spinneret and collector plate to voltage supply. Fixture was fabricated using acrylic material and screw rod was provided with a pitch of $2 \mathrm{~mm}$ for good accuracy. A scale in millimeter was laser engraved for measurement of distance between spinneret and collector plate. Figure 2 represents the basic setup of electrospinning system.

\section{Factors and levels}

The parameters that most often influence the fiber diameter was found to be voltage, tool collector distance and flow rate (Malshe et al. 2011). Hence in the present work, the authors considered three main factors viz. voltage, flow rate and spinneret to collector distance at three levels with fiber diameter as the response factor. Studies were performed using Minitab V-16 software. Experimental analysis Lower the Better (LB) was adopted. The process parameters and their different levels are presented in Table 2.

\section{Design of experiments (DOE)}

Design of Experiments, a statistical tool was adopted to reduce the number of trials and identify the most significant factors affecting the fiber diameter. Taguchi's Orthogonal Array for $\mathrm{L}_{9}$ as shown in Table 3 was used to generate the combination of process parameters for electrospinning.
By the application of Taguchi method, it is possible to control the alternations made by uncontrollable parameters which were not considered in the classical DOE. Taguchi method works by converting the amount of target features to a signal to noise $(S / N)$ ratio for measuring the performance of the level of controlling parameters. Optimization of electrospinning factors and the performance characteristic function that smaller is better was utilized considering the diameter of the fibers.

Table 4 presents factors considered at different levels. The fiber diameter obtained due to variation of process parameters varied between 34.43 and $70.58 \mathrm{~nm}$. Authors randomly selected three different parts of the film for SEM analysis. Table 5 provides a consolidated observation indicating the minimum, maximum, average fiber diameter and percentage bead formation as observed in the SEM images for different experiments. Also authors observed that increase in viscosity of the polymer solution than the optimum value showed the tendency to form more beads in the films (Beachley and Wen 2009). Based on the above fact authors selected the solvent to polymer ratio as $30 \mathrm{~g}: 6 \mathrm{~g}$ by weight. Flow rate was the most influencing parameter for fiber diameter. Defects observed such as bead formation varied with change in voltage, flow rate and spinneret to collector distance as such the parameters are interacting. Figure 3 indicates the variation of fiber diameters for the set of experiments considered for the studies.

Table 6 represents response table for signal to noise ratios of experiments considered. The effect of various parameters on the average fiber diameter was then obtained by calculating the delta value for each parameter, which is the difference between parameters maximum value and minimum value. Higher the value of delta, more is the influence of the parameter on the average fiber diameter. The parameters are ranked in the order of their priority. Thus, flow rate has the highest effect on average fiber diameter followed by the spinneret to collector distance.

\section{Main effects plots}

The overall mean for $S / N$ ratio of average fiber diameter is $-33.95 \mathrm{db}$. The effect of control factors on the average fiber diameter obtained are shown in Figs. 4, 5 and 6. Analysis of results gives the combination of factors resulting in least fiber diameter. The best combination was found to be at $19 \mathrm{kV}$, flow rate $0.5 \mathrm{ml} / \mathrm{h}$ and spinneret to collector distance of $8 \mathrm{~cm}$.

\section{Interaction plots}

The parametric interaction plots are shown in Figs. 7, 8 and 9. Flow rate was found to be critical for minimum value of the fiber diameter, whereas voltage was the least affected 
a
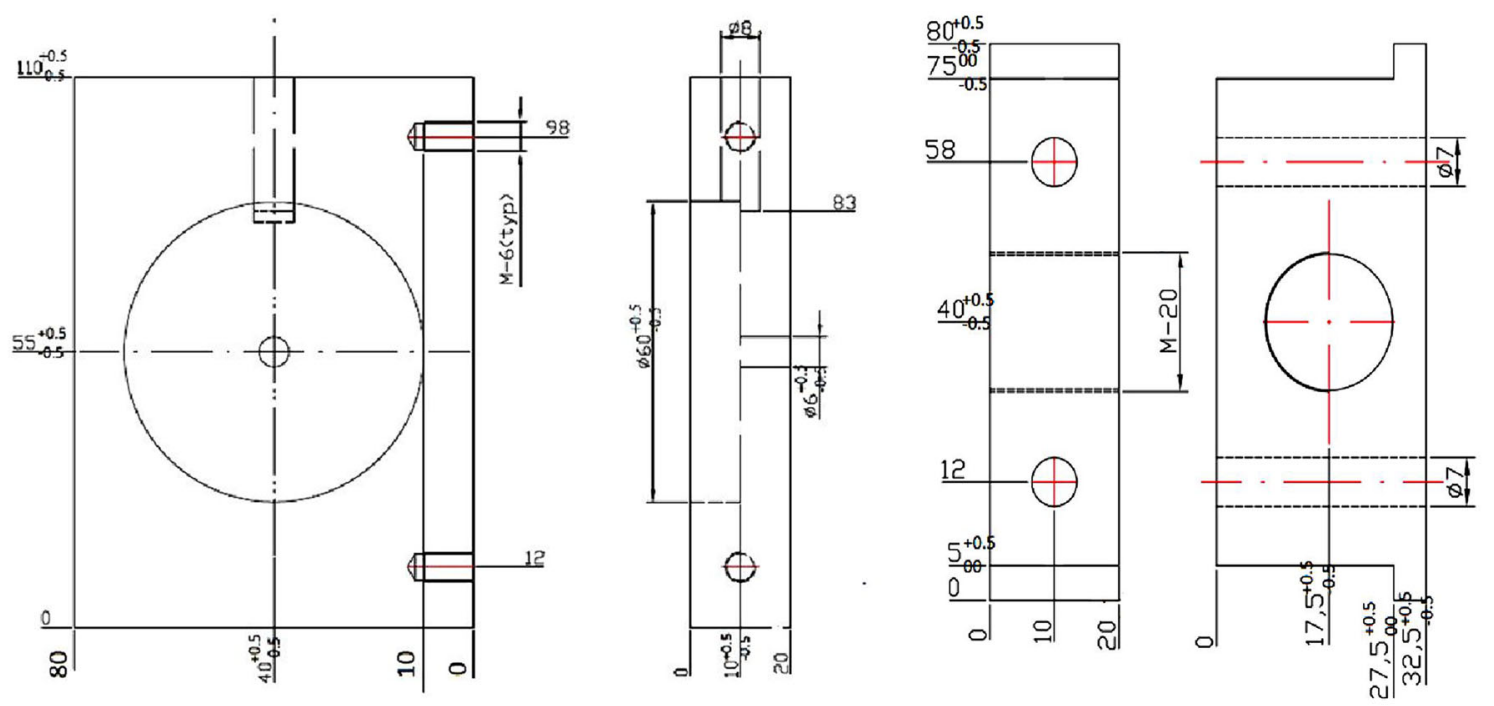

b
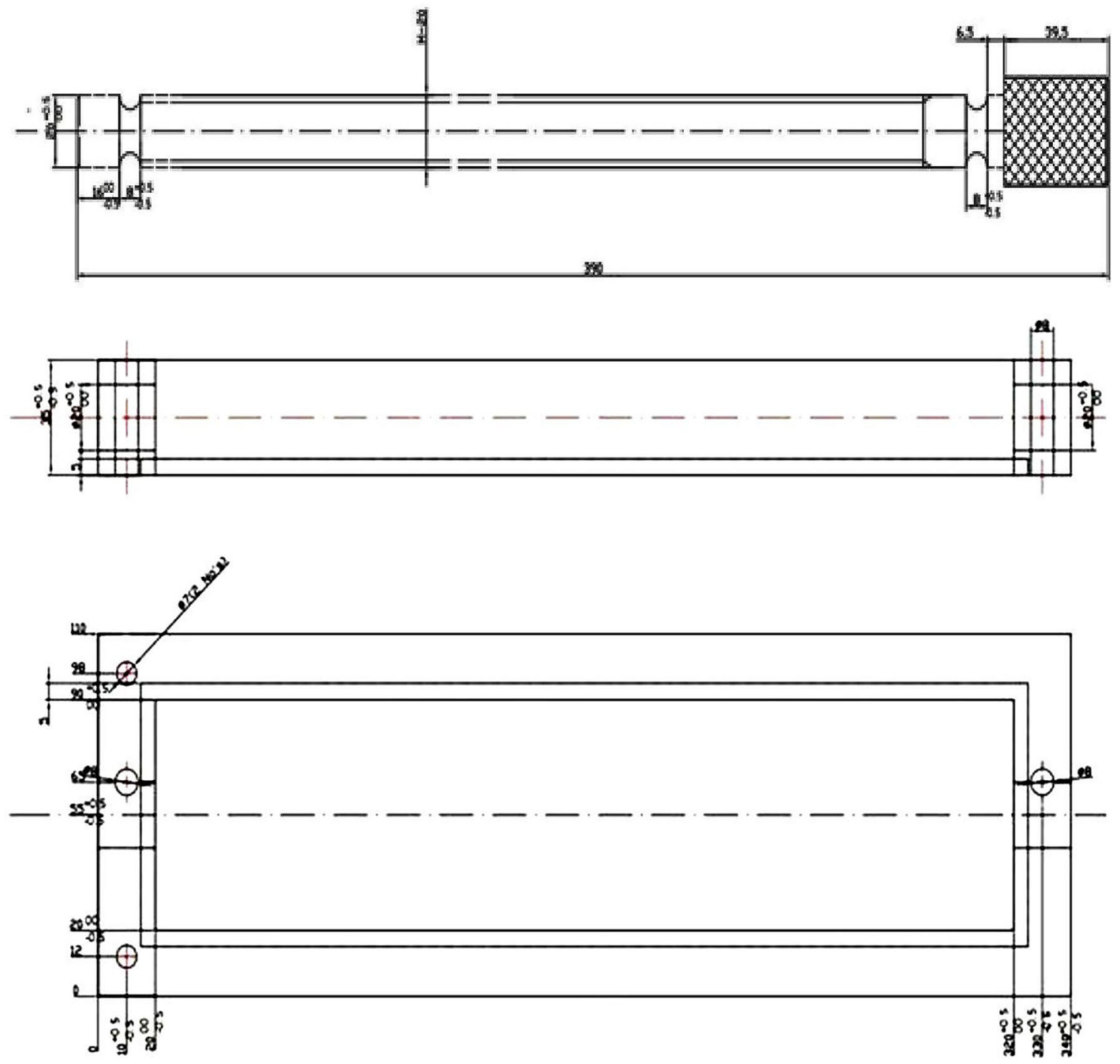

Fig. 1 a Design of spinneret holder and collector plate holder, and $\mathbf{b}$ base of fixture and screw rod 


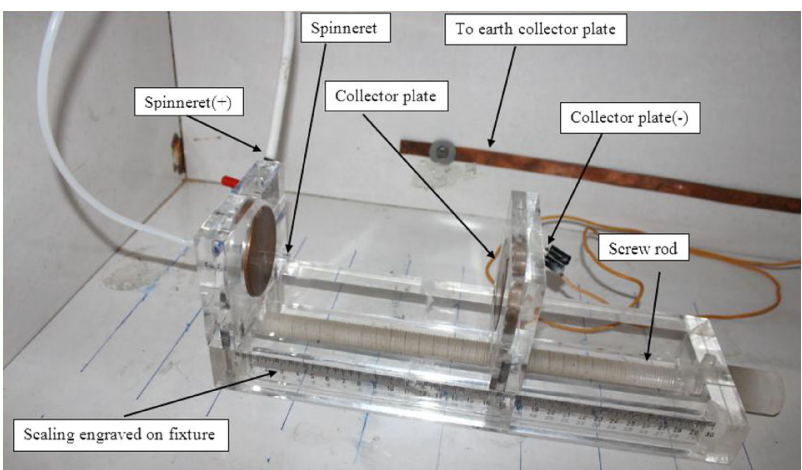

Fig. 2 Basic setup of electrospinning system

Table 2 Parameters and their levels

\begin{tabular}{lllll}
\hline Parameters & Level 1 & Level 2 & Level 3 & Units \\
\hline Voltage & 18 & 19 & 20 & $\mathrm{kV}$ \\
Flow rate & 0.5 & 0.6 & 0.7 & $\mathrm{ml} / \mathrm{h}$ \\
Spinneret to collector distance & 8 & 9 & 10 & $\mathrm{~cm}$ \\
\hline
\end{tabular}

Table 3 Orthogonal Array for L9 Taguchi's experimental design

\begin{tabular}{lllc}
\hline Expt. No. & $\begin{array}{l}\text { Factor } 1 \\
\text { Voltage } \\
(\mathrm{kV})\end{array}$ & $\begin{array}{l}\text { Factor } 2 \\
\text { Flow rate } \\
(\mathrm{ml} / \mathrm{h})\end{array}$ & $\begin{array}{l}\text { Factor } 3 \\
\text { Tool collector } \\
\text { distance }(\mathrm{cm})\end{array}$ \\
\hline 1 & 19 & 0.5 & 8 \\
2 & 19 & 0.6 & 9 \\
3 & 19 & 0.7 & 10 \\
4 & 20 & 0.5 & 9 \\
5 & 20 & 0.6 & 10 \\
6 & 20 & 0.7 & 8 \\
7 & 21 & 0.5 & 10 \\
8 & 21 & 0.6 & 8 \\
9 & 21 & 0.7 & 9 \\
\hline
\end{tabular}

parameter. Voltage and flow rate do not interact with each other to influence the average fiber diameter as observed in Fig. 7. Interaction between voltage and spinneret to collector distance was high as the lines criss-cross each other as seen in Fig. 8. Flow rate and spinneret to collector distance shows minimum interaction and their combined influence on the fiber diameter is minimum as seen from Fig. 9.

\section{SEM images}

SEM characterization of electrospun fibers was performed using SEM model VEGA 3 LMU of TESCAN make (Czech republic) with magnification range of $2.5 \times$ to
Table 4 Process parameters considered at different levels in relationship with average fiber diameter with signal to noise ratio

\begin{tabular}{llcll}
\hline $\begin{array}{l}\text { Voltage } \\
(\mathrm{kV})\end{array}$ & $\begin{array}{l}\text { Flow } \\
\text { rate } \\
(\mathrm{ml} / \mathrm{h})\end{array}$ & $\begin{array}{l}\text { Spinneret to } \\
\text { collector } \\
\text { distance }(\mathrm{cm})\end{array}$ & $\begin{array}{l}\text { Average fiber } \\
\text { diameter }(\mathrm{nm})\end{array}$ & $\begin{array}{l}\text { Signal to } \\
\text { noise ratio } \\
(\mathrm{db})\end{array}$ \\
\hline 19 & 0.5 & 8 & 34.435 & -30.74 \\
19 & 0.6 & 9 & 52.530 & -34.40 \\
19 & 0.7 & 10 & 61.830 & -35.83 \\
20 & 0.5 & 9 & 43.425 & -32.75 \\
20 & 0.6 & 10 & 48.305 & -33.68 \\
20 & 0.7 & 8 & 57.150 & -35.14 \\
21 & 0.5 & 10 & 41.560 & -32.37 \\
21 & 0.6 & 8 & 49.960 & -33.97 \\
21 & 0.7 & 9 & 70.580 & -36.97 \\
\hline
\end{tabular}

Table 5 Minimum and maximum fiber diameter

\begin{tabular}{llllr}
\hline Sample & $\begin{array}{l}\text { Minimum fiber } \\
\text { diameter }(\mathrm{nm})\end{array}$ & $\begin{array}{l}\text { Maximum fiber } \\
\text { diameter }(\mathrm{nm})\end{array}$ & $\begin{array}{l}\text { Average fiber } \\
\text { diameter }(\mathrm{nm})\end{array}$ & $\begin{array}{r}\% \text { of } \\
\text { beads }\end{array}$ \\
\hline 1 & 24.83 & 44.04 & 34.435 & 5.10 \\
2 & 41.70 & 63.36 & 52.53 & 13.86 \\
3 & 57.22 & 66.56 & 61.83 & 17.02 \\
4 & 30.69 & 56.16 & 43.425 & 24.62 \\
5 & 47.82 & 48.79 & 48.305 & 8.20 \\
6 & 51.19 & 63.11 & 57.15 & 11.52 \\
7 & 37.33 & 45.79 & 41.56 & 13.68 \\
8 & 48.37 & 51.55 & 49.96 & 26.05 \\
9 & 49.15 & 92.01 & 70.58 & 12.56 \\
\hline
\end{tabular}

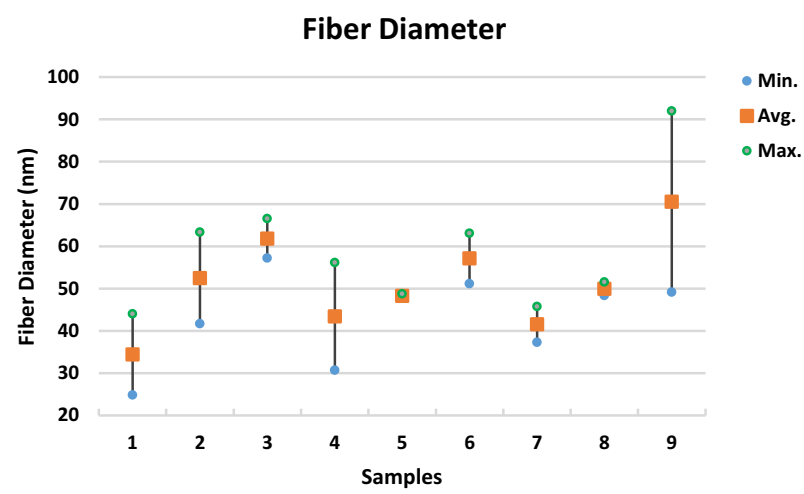

Fig. 3 Fiber diameters of electrospun PVAc samples

$1,000,000 \times$ and resolution $8192 \times 8192$ pixels. Acceleration voltages of 10 and $15 \mathrm{kV}$ were maintained.

It was observed in Fig. 10a that the PVAc/DMF fibers had very few beads and relatively smooth fiber while the fibers were of non-uniform, varying between 25 and $44 \mathrm{~nm}$.

Maintaining lower flow rate provided the solvent enough time to evaporate during the mid-flight between the 
Table 6 Response table for signal to noise ratios of the parameters

\begin{tabular}{lccc}
\hline Level & Voltage $(\mathrm{db})$ & Flow rate $(\mathrm{db})$ & Tip to collector distance $(\mathrm{db})$ \\
\hline 1 & -33.66 & -31.96 & -33.28 \\
2 & -33.86 & -34.02 & -34.71 \\
3 & -34.44 & -35.98 & -33.96 \\
Delta & 0.78 & 4.02 & 1.43 \\
Rank & 3 & 1 & 2
\end{tabular}

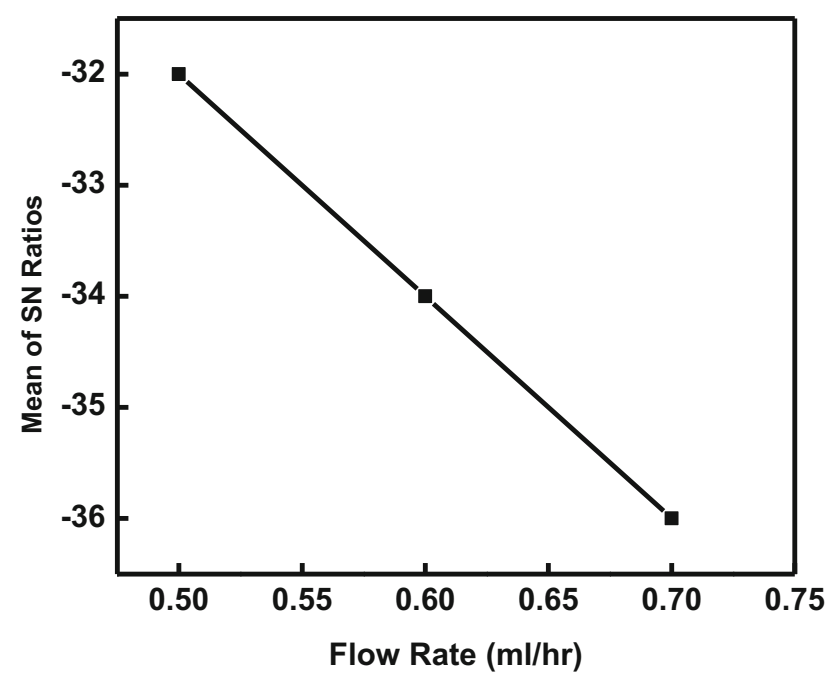

Fig. 4 Main effect plot of $S / N$ ratio vs. flow rate

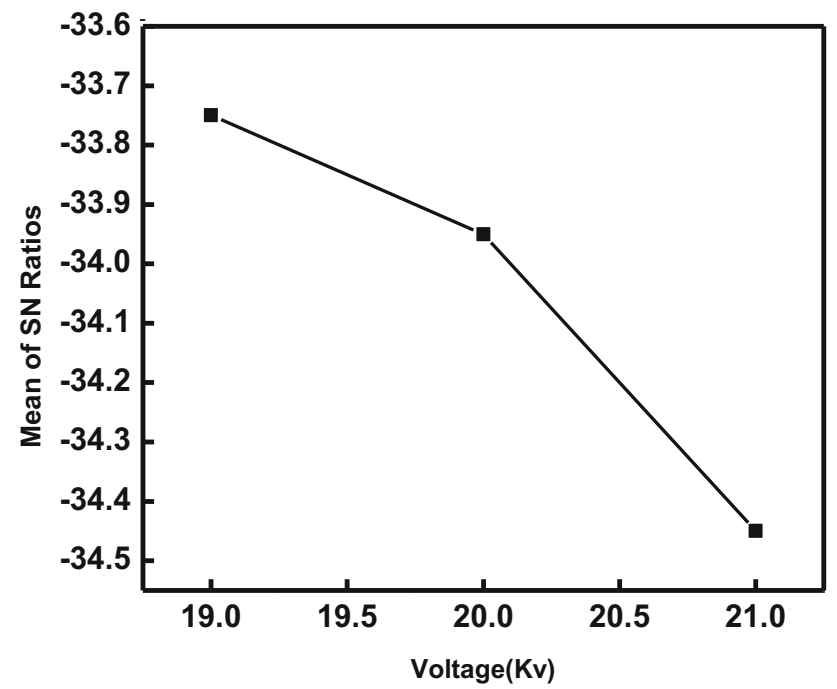

Fig. 5 Main effect plot of $S / N$ ratio vs. voltage

tips of the spinneret to the collector surface. Thus, the beads formed were found to be minimum. Figure 10b shows beads had increased in number and the size of the beads also increased. A network of fibers could be observed along with beads. Figure 10c show intensive bead

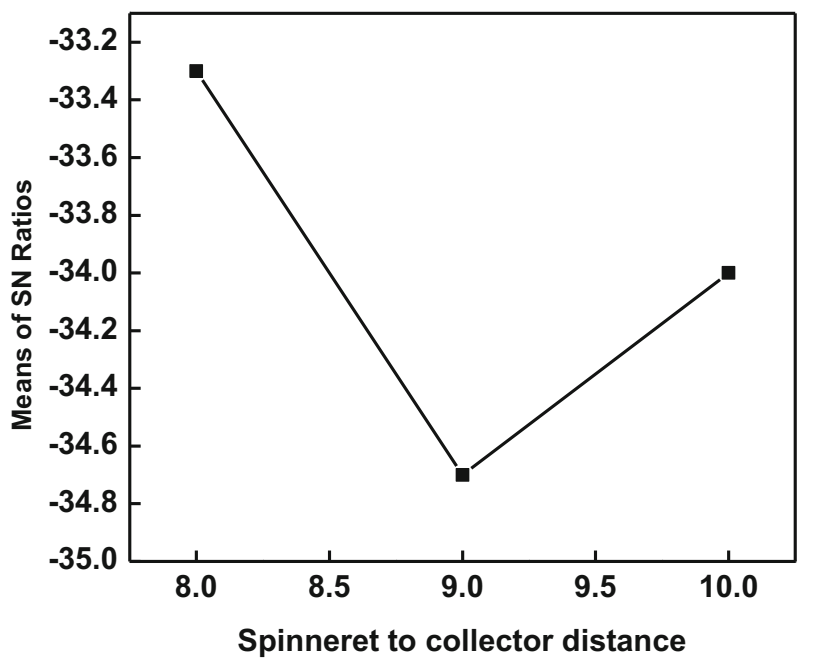

Fig. 6 Main effect plot of $S / N$ ratio vs. spinneret to collector distance

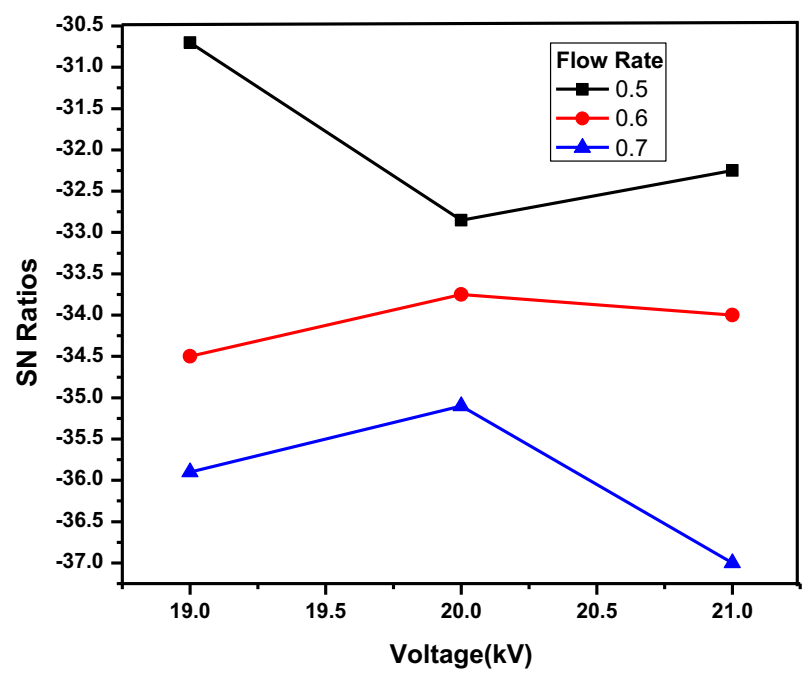

Fig. 7 Interaction plot of $S / N$ ratio of flow rate vs. voltage

formation. The fiber density increased as well as the fiber networking. Dimensions of the beads were large suggesting merger of two or more beads to form the structure. Fiber diameter ranged between 58 and $67 \mathrm{~nm}$. Figure 10d shows beads formed were significant in number and size, with relative increase in fiber density.

Figure 11a indicates fibers were more uniform in diameter. Fiber diameter was close to $48 \mathrm{~nm}$ and decrease in fiber density with bead formations. Figure $11 \mathrm{~b}$ indicates intense bead formation with fiber criss-cross. The fiber density increased but the uniformity of fiber diameter decreased. Figure 11c indicates bead density was low and the fibers were more uniform with dimensions between $37 \mathrm{~nm}$ and $46 \mathrm{~nm}$ suggesting decrease in fiber diameter as compared to sample (b). Figure $11 \mathrm{~d}$ indicates the intensity of fiber networking increased along with formation of beads. The range of fiber diameter was 


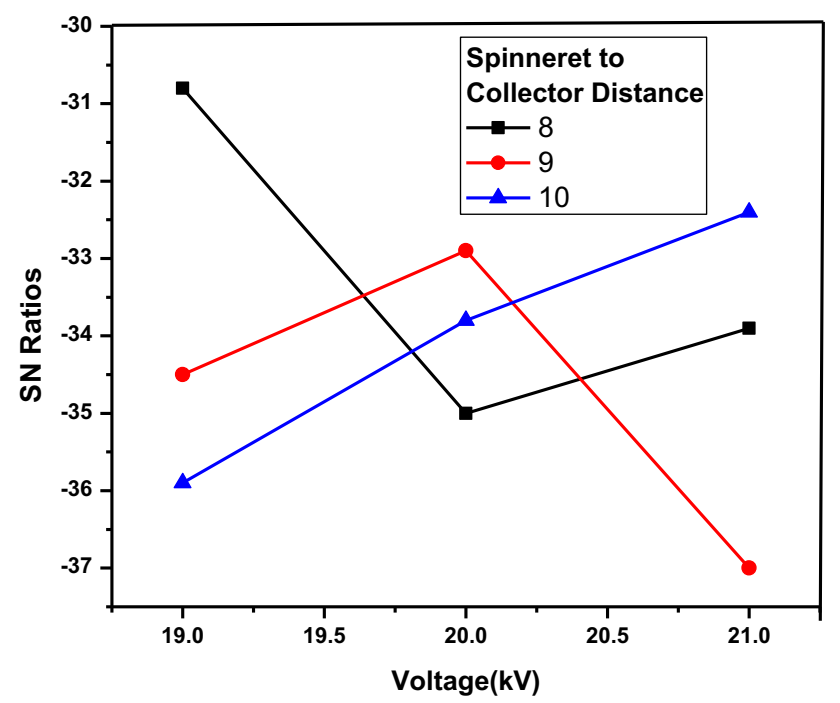

Fig. 8 Interaction plot of $S / N$ ratio of spinneret to collector distance vs. voltage

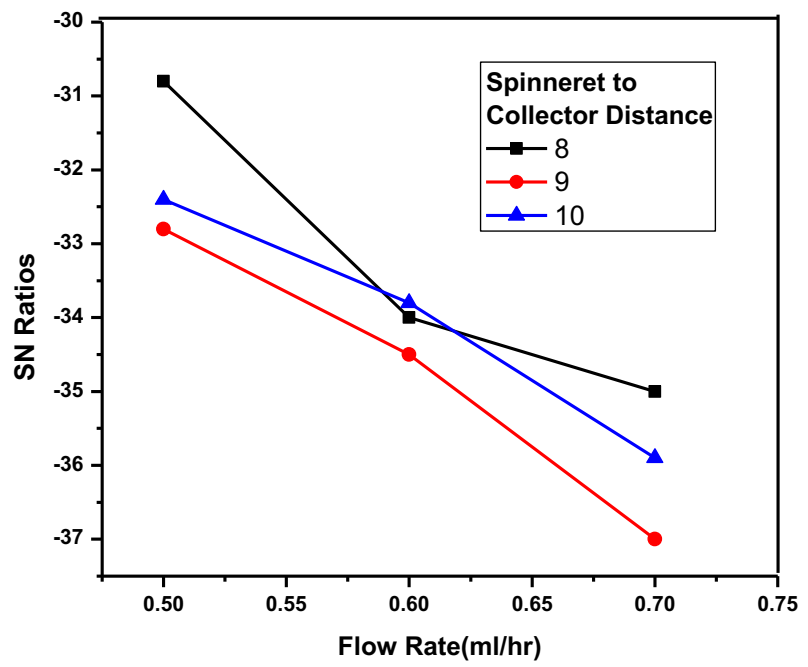

Fig. 9 Interaction plot of $S / N$ ratio of spinneret to collector distance vs. flow rate
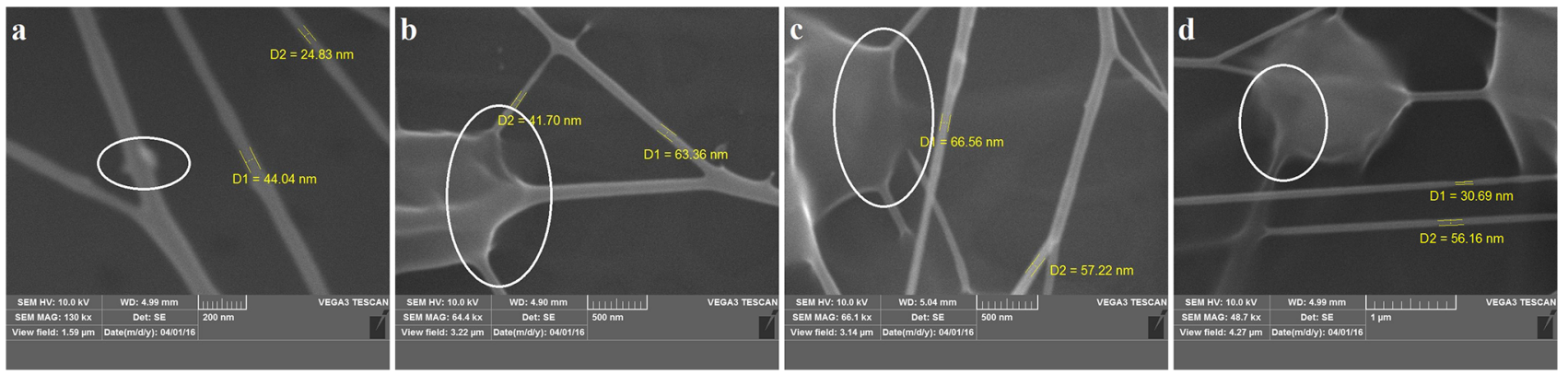

Fig. 10 SEM images of electrospun fibers of PVAc/DMF in $6 \mathrm{~g} / 30 \mathrm{ml}(\mathrm{w} / \mathrm{v})$ concentration a $19 \mathrm{kV}, 0.5 \mathrm{ml} / \mathrm{h}$ and $80 \mathrm{~mm}, \mathbf{b} 19 \mathrm{kV}, 0.6 \mathrm{ml} / \mathrm{h}$ and $90 \mathrm{~mm}, \mathbf{c} 19 \mathrm{kV}, 0.7 \mathrm{ml} / \mathrm{h}$ and $100 \mathrm{~mm}$, and $\mathbf{d} 20 \mathrm{kV}, 0.5 \mathrm{ml} / \mathrm{h}$ and $90 \mathrm{~mm}$ between 49 and $52 \mathrm{~nm}$ indicating fiber uniformity due to high voltage.

High-density fibers along with beads were observed at higher flow rate of $0.7 \mathrm{ml} / \mathrm{h}$. This is due to insufficient time for evaporation of the solvent from the polymer prior to reaching the collector. It also caused non-uniformity in the fiber diameter. As fibre diameter decreases the packing density and surface area of the fibers increase, (Xiang and Frey 2016). Polymer films with greater surface area of fibers perform better as sensors. Deposition rate of fibers depends on the viscosity, flow rate and tip to collector distance. Higher viscosity causes beads. Electrospun nanofibre average diameter of PVAC synthesized in the present research, i.e., $38-78 \mathrm{~nm}$ is comparable with those of the commercially available systems reported in elsewhere studies, i.e., $300 \mathrm{~nm}$ reported by (Jannesari et al. 2011) and $200 \mathrm{~nm}$ reported by (Sharma et al. 2013) for the same polymer and 85-105 $\mathrm{nm}$ reported by (Supaphol and Chuangchote 2008) and 150-200 nm reported by (Oktay et al. 2014) for Poly vinylalcohol.

\section{Conclusion}

Electrospinning system for processing of polymer nanofibers was fabricated. PVAc electrospun fibers had diameter consistently less than $100 \mathrm{~nm}$. Although bead formation was observed in most of the samples, their dimensions varied with process parameters. Least diameter of $24.83 \mathrm{~nm}$ was observed at $19 \mathrm{kV}, 0.5 \mathrm{ml} / \mathrm{h}$ flow rate and $8 \mathrm{~cm}$ spinneret to collector distance and maximum of $92.01 \mathrm{~nm}$ at $21 \mathrm{kV}, 0.7 \mathrm{ml} / \mathrm{h}$ flow rate and $8 \mathrm{~cm}$ spinneret to collector distance. Design of Experiments was used to investigate the cause-and-effect relationships. Ranking of the experimental results of fiber diameter indicated that flow rate was highly a significant factor on controlling fiber diameter followed 

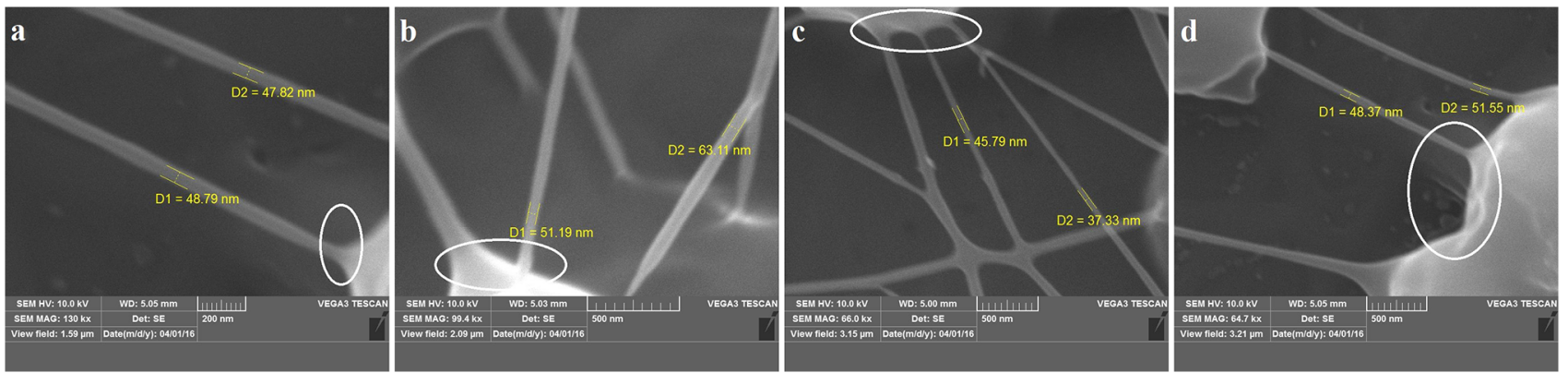

Fig. 11 SEM images of electrospun fibers of PVAc/DMF in $6 \mathrm{~g} / 30 \mathrm{ml}(\mathrm{w} / \mathrm{v})$ concentration a $20 \mathrm{kV}, 0.6 \mathrm{ml} / \mathrm{h}$ and $100 \mathrm{~mm}, \mathbf{b} 20 \mathrm{kV}, 0.7 \mathrm{ml} / \mathrm{h}$ and $80 \mathrm{~mm}, \mathbf{c} 21 \mathrm{kV}, 0.5 \mathrm{ml} / \mathrm{h}$ and $100 \mathrm{~mm}$, and d $21 \mathrm{kV}, 0.6 \mathrm{ml} / \mathrm{h}$ and $80 \mathrm{~mm}$

by spinneret to collector distance. SEM images revealed uniform fiber diameter at lower flow rate while bead formation increased monotonically with rise in flow rate.

Open Access This article is distributed under the terms of the Creative Commons Attribution 4.0 International License (http:// creativecommons.org/licenses/by/4.0/), which permits unrestricted use, distribution, and reproduction in any medium, provided you give appropriate credit to the original author(s) and the source, provide a link to the Creative Commons license, and indicate if changes were made.

\section{References}

Albetrana H, Dongc Y, Low IM (2015) Characterization and optimization of electrospun $\mathrm{TiO}_{2} / \mathrm{PVP}$ nanofibers using Taguchi design of experiment method. J Asian Ceram Soc 3(3):292-300. doi:10.1016/j.jascer.2015.05.001

Beachley V, Wen X (2009) Effect of electrospinning parameters on the nanofiber diameter and length. Mater Sci Eng C 29(3):663-668. doi:10.1016/j.msec.2008.10.037

Chaudhary AR, Ahuja BB (2014) Characterization and optimization of electrospun polyacrylonitrile (PAN) and polyvinylidene fluoride (PVDF) nanofibers. In: 5th International \& 26th All India manufacturing technology, design and research conference (AIMTDR 2014), IIT Guwahati, Assam, India. ISBN: 978-819274-610-4

Cui X, Luming L, Xu F (2011) Controlled assembly of poly (vinyl pyrrolidone) fibers through an electric-field-assisted electrospinning method. Appl Phys 103:167-172. doi:10.1007/s00339-0106036-y

Dinga B, Sun G, Wang M, Yub J (2009) Gas sensors based on electrospun nanofibers. Sensors 9:1609-1624. doi:10.3390/s90301609

Dinga B, Suna G, Wangc M, Wanga X, Yub J (2010) Electrospun nanomaterials for ultrasensitive sensors. Mater Today 13(11):16-27. doi:10.1016/s1369-7021(10)70200-5

Ghanbari D, Beshkar F, Khaghani S, Niasari MS (2016) Preparation of PVAc (PVAc) and PVAc- $\mathrm{Ag}-\mathrm{Fe}_{3} \mathrm{O}_{4}$ composite nanofibers by electro-spinning method. J Cluster Sci. doi:10.1007/s10876-016$1002-2$

Jannesari M, Morshed M, Varshosaz J, Zamani M (2011) Composite poly(vinyl alcohol) poly(vinyl acetate) electrospun nanofibrous mats as a novel wound dressing matrix for controlled release of drugs. Int J Nanomedicine Publisher. Dove Medical Press: 993-1003. doi:10.2147/ijn.s17595
Khanlou HM, Ang BC (2014) Electrospinning of polymethyl methacrylate nanofibers: optimization of processing parameters using the Taguchi design of experiments. Text Res J. doi:10. $1177 / 0040517514547208$

Kiyak YEN, Cakmak E (2014) Nanofiber production methods. Electron J Text Technol 8(3):49-60 (ISSN: 1309-3991)

Malshe H, Jiang W, Malshe AP (2011) Design, fabrication, and testing of an electrospinning apparatus for the deposition of PMMA polymer for future biomedical applications. Inquiry $\mathbf{J}$ 12(11):70-76

Mirmohseni A, Oladegaragoze A (2003) Construction of a sensor for determination of ammonia and aliphatic amines using polyvinylpyrrolidone coated quartz crystal microbalance. Sens Actuators B 89(1-2):164-172. doi:10.1016/s0925-4005(02) 00459-8

Nirmala R, Jeon KS, Kim HY, Navamathavan R, Park SJ (2014) Synthesis and characterization of electrospun cadmium sulfideand lead sulfide blended poly (vinylacetate) composite nanofibers. Mater Sci Semicond Process 26:575-582. doi:10.1016/j. mssp.2014.05.038

Oktay B, Apohan NK, Kuruca SE (2014) Fabrication of nanofiber mats from electrospinning of functionalized polymers. In: IOP conference series: material science engineering 2nd international conference on structural nano composites (NANOSTRUC 2014): 1-5. doi:10.1088/1757-899X/64/1/012011

Pankonian A, Ounaies Z, Yang C (2011) Electrospinning of cellulose and SWNT-cellulose nano fibers for smart application. J Mech Sci Tech 25(10):2631-2639. doi:10.1007/s12206-011-0736-x

Park JY, Bea GN, Lee IH (2008) Optimization of the electrospinning conditions for preparation of nanofibers from polyvinylacetate (PVAc) in ethanol solvent. J Ind Eng Chem. doi:10.1016/j.jiec. 2008.03.006

Park JY, Lee IH, Shim WG (2011) Modeling and optimization of electrospun polyvinylacetate (PVAc) nanofibers by response surface methodology (RSM). J Nanosci Nanotechnol 11(2):1359-1363. doi:10.1063/1.3604491

Petrasa D, Kimmer D, Pavlíneka V, Sáhaa P, Slobodiana P (2011) The Effect of PVAc Solution Viscosity on Diameter of PVAc Nanofibers Prepared by Technology of Electrospinning. Am Inst Phys Conf Proc 1375(312):312-319. doi:10.1063/1.3604491

Pise DD, Ahuja BB, Shendokar SM (2013) Study of process parameters affecting the diameter and morphology of electrospun polyvinylidene fluoride (PVDF) nanofibers. Int J Sci Res 4(6):155-160 (ISSN: 2319-7064)

Sharma S, Natarajan TS, Rani R, Rai R (2013) Synthesis and characterization of $\mathrm{CuO}$ electrospum nanofiber using poly (vinylacetate) $/ \mathrm{Cu}\left(\mathrm{CH}_{3} \mathrm{COO}\right)_{2}$ annealing method. Adv Mat Lett 4(10):749-753. doi:10.5185/amlett.2013.2425 
Supaphol P, Chuangchote S (2008) On the electrospinning of poly(vinyl alcohol) nanofiber mats. J Appl Polym Sci 108:969-978. doi:10.1002/app.27664

Teo WE, Inai R, Ramakrishna S (2011) Technological advances in electrospinning of nanofibers. Sci Tech Adv Mater. doi:10.1088/ 1468-6996/12/1/013002

Wang XF, Dinga B, Yub J (2012) Functional nanofibers in sensor applications. Functional nanofibers and their applications. In: A volume in Wood head Publishing Series in Textiles. Elsevier, Donghua University, China, pp 209-235. doi:10.1533/ 9780857095640.2.209

Xiang C, Frey Margaret W (2016) Increasing mechanical properties of 2-D-structured electrospun nylon 6 non-woven fiber mats. Mater MDPI 9:1-13. doi:10.3390/ma9040270 